\title{
POPULATION STUDY ARTICLE Timely initiation of breastfeeding among first time mothers in Bahir Dar city, North West, Ethiopia, 2016
}

Tilksew Ayalew ${ }^{1}$, Tilahun Tewabe ${ }^{2}$ and Yohannis Ayalew ${ }^{3}$

BACKGROUND: Timely initiation of breastfeeding is one important intervention to prevent childhood morbidities and mortalities. Globally, not more than 35 and 39\% in developing countries, 52\% in Ethiopia and 38\% in Amhara region were initiated with breastfeeding early.

METHODS: A community based cross-sectional study was conducted from 20 March to April, 2016. A total of 423 mothers who have infants less than 6 month old were included in this study. The data were collected using interviewer administered questionnaire. Binary logistic regression analysis were used to identify factors associated with timely initiation of breastfeeding. RESULTS: Prevalence of timely initiation of breastfeeding was $65 \%$. Being male [AOR $2.148(1.232,3.745)]$, breastfeeding counseling [AOR $2.163(1.187,3.942)]$, place of delivery [AOR $8.639(2.089,5.720)]$, normal labor [AOR $4.094(1.414,8.728]$, and religious father support [AOR $1.962(1.113,3.458)]$ were determinants for timely initiation of breastfeeding.

CONCLUSIONS: Timely initiation of breastfeeding in the study area was $65 \%$. Sex of infant, breastfeeding counseling, birth place, mode of delivery, and religious father support were predictors of timely initiation of breastfeeding. Strengthening timely initiation of breastfeeding through provision of antenatal care services, educating mothers and strengthening health professionals knowledge, and skills on breastfeeding counseling were recommended.

Pediatric Research (2019) 85:612-616; https://doi.org/10.1038/s41390-019-0299-6

\section{INTRODUCTION}

Suboptimal infant feeding is responsible for $45 \%$ of neonatal infectious deaths, $30 \%$ of diarrheal deaths and $18 \%$ of acute respiratory deaths in children under 5 years worldwide. ${ }^{1}$

Starting breastfeeding in the first day after birth can reduce the risk of newborn death by up to $45 \%$ and children who are exclusively breastfed are 14 times more likely to survive the first 6 months of life than non-breastfed children. ${ }^{2}$

Late initiation and non-exclusive breastfeeding is known to compromise the nutritional status of infants and children. It results in an estimated $40 \%$ of under-five stunting in western and central Africa and more than $60 \%$ in some other countries. ${ }^{3}$

Early initiation of breastfeeding has a great impact on the reduction of neonatal mortality and morbidity. ${ }^{4}$ But many factors have found to affect timely initiation of breastfeeding like; societal beliefs favoring to start with other feeding, lack of adequate support in health facilities and in the community, aggressive promotion of infant formula through medias, and lack of knowledge on the dangers of artificial feeding among women, their partners, and families. ${ }^{5}$

In Ethiopia children suffer from poor health. About 472,000 children die each year before their fifth birth day making Ethiopia sixth among the countries of the world in terms of the absolute number of child deaths. The age distribution of under five deaths was $29 \%$ in the first 30 days of life, $29 \%$ from the first month to the $11^{\text {th }}$ month of life, and $42 \%$ from the first year to the fourth year. Neonatal mortality is very high in Ethiopia making Ethiopia $5^{\text {th }}$ in the world in neonatal mortality and children in Ethiopia are still dying in large numbers from preventable and treatable conditions later in childhood. ${ }^{6}$

In Ethiopia more than half (57\% in urban and $51 \%$ in rural) of the newborns of both primipara and multipara mothers are not breastfed within $1 \mathrm{~h}$ from birth. ${ }^{7}$ The pooled prevalence of timely initiation of breastfeeding in Ethiopia was $61.4 \%,{ }^{8}$ and the prevalence of timely initiation of breastfeeding in other places of Ethiopia; $78.8 \%$ in Motta, ${ }^{9} 77 \%$ in Mekele, ${ }^{10} 73.1 \%$ in Dembecha, ${ }^{11}$ $62.6 \%$ in Debre Berhan town, ${ }^{12} 52.4 \%$ in Goba district, ${ }^{13} 42.8 \%$ in Arba Minch Zuria ${ }^{14}$, and $32.7 \%$ in Tiyo Woreda. ${ }^{15}$ But there was no any study in the country which depicts the timely initiation of breastfeeding practices and associated factors among first time mothers. This study, therefore, sought to assess initiation of breastfeeding practices and associated factors among first time mothers Bahir Dar City, North West Ethiopia.

\section{METHODS}

Study area and setting

This community based cross sectional study was conducted from March 2016 to April 2016. The study was conducted in Bahir Dar city which is located in Amhara National Regional State, Ethiopia. The city is located approximately $578 \mathrm{~km}$ Northwest of Addis Ababa. Based on the 2007 census conducted by the Central Statistical Agency of Ethiopia (CSA), Bahir Dar special zone has a total population of 221,991 , of whom 108,456 were men and 113,535 were women in which around 75,690 were women with reproductive age group. ${ }^{16,17}$

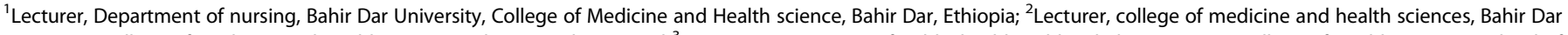

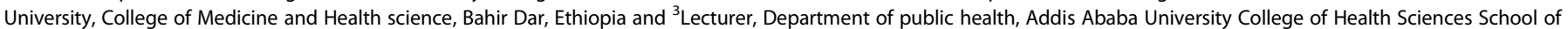
Allied Health Sciences, Addis Ababa, Ethiopia

Correspondence: Tilahun Tewabe (bezatewabe01@gmail.com)

Received: 11 October 2018 Revised: 6 January 2019 Accepted: 7 January 2019

Published online: 19 January 2019 
Timely initiation of breastfeeding among first time mothers in Bahir Dar... $\mathrm{T}$ Ayalew et al.

Sample size and sampling procedure

The sample size was calculated using single population proportion formula $\mathrm{n}=\frac{z^{2} \alpha / 2 \times p(1-P)}{d^{2}}$ by considering the following assumptions: prevalence $(P)=50 \%$, level of confidence $=95 \%$, level of significance $=5 \%$, and margin of error $(d)=5 \%$ and after considering 10\% non-response rate, the final sample size became 423 .

All nine sub cities (Tana, Belay Zeleke, Hidar-eleven, Fasilo, Ginbot-20, Gish bay, shumabo, shimbit, and sefeneselam) were included in the study. The registration of first time mothers who had a child less than 6 months, gained from local health extension workers, was used to get the list of children in each sub city. Then, sample from each sub city was determined using proportional allocation to size (PAS). Finally, study subjects were selected by using simple random sampling technique i.e., a lottery method was used.

A structured interviewer administered questionnaire was used to collect data from participants or mothers of a child. It was constructed by adopting and modifying from previous researches done on similar topics. ${ }^{18,19}$ First, the English version of the questionnaire was prepared. Then it was translated to Amharic version (local language) and translated back to English after completion. The questionnaire consists of five parts: sociodemographic characteristics of the respondents, maternity and maternal/infant health service utilization questions, breastfeeding related questions, sources of information and timely initiation of breastfeeding knowledge questions, and barriers to timely initiation of breastfeeding.

Six diploma nurses were recruited as data collectors and two other bachelor nurses were recruited as supervisors. All data collectors and supervisors were oriented and trained on how to interview and record the data for a day. The validity and reliability of the instrument was checked by pilot test on $5 \%$ of the calculated sample size of mothers those who were not the actual study participant and adjustment was made based on the results of the pilot test.

Operational definitions

Timely initiation of breastfeeding: if an infant within $1 \mathrm{~h}$ of birth is put on the mother's breast to feed. ${ }^{9,13,20}$

Adequate knowledge about breastfeeding: if a mother correctly answers three or more amongst the five questions she was considered as knowledgeable. ${ }^{9}$

Data processing and analysis

The collected data were checked manually for completeness and consistencies, and then coded and entered in EPI Info version 7 and transferred to SPSS version 20 for analysis. Descriptive statistics were used to summarize the socio-demographic characteristics' of the study participants and the prevalence of timely initiation of breastfeeding. To identify factors associated with timely initiation of breastfeeding practice, binary logistic regression analysis was carried at two levels, first bivariate logistic regression was performed to each independent variable with the outcome variable and those variables with a $p$ value $<0.2$ were included in the final model. Strength of association was measured using odds ratio, and $95 \%$ confidence intervals. Statistical significance was declared at $P$ value $<0.05$.

\section{RESULTS}

Socio-demographic characteristics

Out of 423 mothers, 400 agreed to participate in this study, which made a response rate $95.0 \%$. The mean age of mothers was 26 years (standard deviation, $\mathrm{SD} \pm 4.08)$. Around half $(48 \%)$ of mothers were aged between 25-29 years. More than two third (69\%) of mothers were Orthodox Christian followers. Regarding to educational status, $132(50.3 \%)$ mothers were not educated. Majority (73.8\%) of participants were unemployed.
Table 1. Socio-demographic Characteristics of mothers with their infants aged less than six months old, in Bahir Dar City, Amhara Regional, North west State Ethiopia, $2016(n=400)$

\begin{tabular}{|c|c|c|c|}
\hline Variable & Category (n400) & Frequency & Percent \\
\hline \multirow[t]{3}{*}{ Religion } & Orthodox & 279 & $69.0 \%$ \\
\hline & Muslim & 95 & $23.7 \%$ \\
\hline & Others $^{a}$ & 29 & $7.20 \%$ \\
\hline \multirow[t]{3}{*}{ Ethnicity } & Amhara & 349 & $87.3 \%$ \\
\hline & Oromo & 33 & $8.3 \%$ \\
\hline & Others $^{\mathrm{b}}$ & 18 & $4.5 \%$ \\
\hline \multirow{2}{*}{$\begin{array}{l}\text { Level of education of } \\
\text { mother }\end{array}$} & Uneducated & 201 & $50.3 \%$ \\
\hline & Educated & 199 & $49.7 \%$ \\
\hline \multirow{2}{*}{$\begin{array}{l}\text { Occupational status of } \\
\text { mother }\end{array}$} & Employed & 295 & $73.8 \%$ \\
\hline & Unemployed & 105 & $26.2 \%$ \\
\hline \multirow[t]{2}{*}{ Current marital status } & Married & 346 & $86.5 \%$ \\
\hline & $\begin{array}{l}\text { Unmarried// } \\
\text { separated }^{\mathrm{c}}\end{array}$ & 54 & $13.5 \%$ \\
\hline \multirow{2}{*}{$\begin{array}{l}\text { Husband educational } \\
(n=346)\end{array}$} & Uneducated $^{d}$ & 110 & $31.8 \%$ \\
\hline & Educated & 236 & $68.2 \%$ \\
\hline \multirow{2}{*}{$\begin{array}{l}\text { Husband occupation } \\
(n=346)\end{array}$} & Employed & 185 & $53.4 \%$ \\
\hline & Unemployed & 161 & $46.6 \%$ \\
\hline \multirow[t]{3}{*}{ Household income } & $\leq 500$ & 3 & $0.75 \%$ \\
\hline & $501-1499$ & 32 & $8.0 \%$ \\
\hline & $\geq 1500$ & 366 & $91.5 \%$ \\
\hline \multicolumn{4}{|c|}{$\begin{array}{l}\text { aProtestant, Catholic, Jhova, Other } \\
\text { b Agew, Tgirie, Gurage, other } \\
{ }^{\mathrm{c} S i n g l e, ~ w i d o w e d, ~ s e p a r a t e d ~} \\
{ }^{\mathrm{d}} \text { Mothers with no high school education }\end{array}$} \\
\hline
\end{tabular}

The average household income of the respondents was 3762 Ethiopian birr per month with standard deviation (SD \pm 2136.48 ) (Table 1).

Infant and maternal health service utilization characteristics and breastfeeding and related practices

About 210 (52.5\%) infants were aged between 0-2.9 months old. Majority (90.8\%) of mothers received antenatal care (ANC) during their period of pregnancy and out of them only 277 (76.3\%) were counseled about breastfeeding. Regarding to place of delivery, majority $(93.8 \%)$ of mothers delivered in health institution. Most $(82.2 \%)$ of mothers were attended by normal/vaginal delivery. Majority $(91.2 \%)$ of mothers fed first milk/colostrums to their infant. Majority (93.8\%) did not give prelacteal foods other than breast milk soon after delivery. Prevalence of timely initiation of breastfeeding practice within $1 \mathrm{~h}$ of delivery was $65 \%$. Among mothers who did not initiate breastfeeding within $1 \mathrm{~h}$ of delivery, major reasons were; tradition/culture(48.0\%), perception of it is not good for the infant $(28.6 \%)$. Most $(89.5 \%)$ of mothers were supported by their husband to initiate breastfeeding timely. Few (13.0\%) have got support from cultural system of their community. Among those faced breast problem, mastitis $(57.1 \%)$ is the most common problem faced mothers. Regarding to management of the problem, about two third (57.8\%) of mothers prefer others than going to health facility like expressing breast milk, rubbing by local herbs. Lack of information (59.8\%) is the most common barrier for timely initiation of breastfeeding as mentioned by participant mothers (Table 2).

Information and knowledge of breastfeeding of mothers Regarding to information about timely initiation of breastfeeding, $345(86.25 \%)$ mothers were informed about timely initiation of 
Table 2. Maternity and infant health service utilization characteristics, breastfeeding related variables of study Participants in Bahir Dar City, Amhara Regional State, North west Ethiopia, $2016(n=400)$

\begin{tabular}{|c|c|c|c|}
\hline Variable & Response (n400) & Frequency & Percent \\
\hline \multirow[t]{2}{*}{ Sex of children } & Male & 214 & $53.5 \%$ \\
\hline & Female & 186 & $46.5 \%$ \\
\hline \multirow[t]{2}{*}{ Age of children } & 0-2.9 month & 210 & $52.5 \%$ \\
\hline & 3-5.9 month & 190 & $47.5 \%$ \\
\hline \multirow[t]{2}{*}{ ANC follow up } & Yes & 363 & $90.8 \%$ \\
\hline & No & 37 & $9.2 \%$ \\
\hline \multirow[t]{2}{*}{ Number of ANC follows up } & $\leq 3$ times & 133 & $36.6 \%$ \\
\hline & $\geq 4$ times & 230 & $63.4 \%$ \\
\hline \multirow[t]{2}{*}{ Counseling during ANC } & Yes & 277 & $76.3 \%$ \\
\hline & No & 86 & $23.7 \%$ \\
\hline \multirow[t]{2}{*}{ Place of birth } & Health Institution & 375 & $93.8 \%$ \\
\hline & Home & 25 & $6.2 \%$ \\
\hline \multirow[t]{2}{*}{ Mode of delivery } & Vaginal/Normal & 329 & $82.2 \%$ \\
\hline & Cesarean section & 71 & $17.8 \%$ \\
\hline \multirow{2}{*}{$\begin{array}{l}\text { Timely initiation of } \\
\text { breastfeeding }\end{array}$} & $<1 \mathrm{~h}$ & 260 & $65.0 \%$ \\
\hline & $>1 \mathrm{~h}$ & 140 & $35.0 \%$ \\
\hline \multirow[t]{4}{*}{ Reasons not timely initiate } & $\mathrm{C} / \mathrm{s}$ delivery & 207 & $51.8 \%$ \\
\hline & Child illness & 75 & $18.8 \%$ \\
\hline & Maternal illness & 24 & $6.0 \%$ \\
\hline & $\begin{array}{l}\text { Delayed milk } \\
\text { secretion }\end{array}$ & 94 & $23.5 \%$ \\
\hline \multirow{2}{*}{$\begin{array}{l}\text { First milk/colostrums } \\
\text { feeding }\end{array}$} & Yes & 365 & $91.2 \%$ \\
\hline & No & 35 & $8.8 \%$ \\
\hline \multirow{2}{*}{$\begin{array}{l}\text { Other feeding before } \\
\text { breastfeeding }\end{array}$} & No & 375 & $93.8 \%$ \\
\hline & Yes & 25 & $6.2 \%$ \\
\hline \multirow[t]{2}{*}{ Any breast problem } & Yes & 49 & $12.2 \%$ \\
\hline & No & 351 & $87.8 \%$ \\
\hline \multirow[t]{2}{*}{ Husband support ( $n=346)$} & Yes & 310 & $89.5 \%$ \\
\hline & No & 36 & $10.5 \%$ \\
\hline \multirow[t]{2}{*}{ Religious father support ${ }^{a}$} & Yes & 165 & $41.3 \%$ \\
\hline & No & 235 & $58.7 \%$ \\
\hline \multirow[t]{2}{*}{ Cultural support } & Yes & 52 & $13.0 \%$ \\
\hline & No & 348 & $87.0 \%$ \\
\hline
\end{tabular}

${ }^{\text {a }}$ Religious father who supports, encourages and promotes the mother breastfeeding

breastfeeding from different sources. Majority (78.8\%) of mothers had adequate knowledge about breastfeeding.

Factors associated with timely initiation of breastfeeding After adjusting confounding factors, in multivariate logistic regression analysis; sex of infant, breastfeeding counseling during ANC, birth place, mode of delivery, and religious father support remained significant in the final model.

Sex of infant was associated with timely initiation of breastfeeding. Mothers who had a male baby were two times more likely to initiate breastfeeding than mothers who had a female baby $[\mathrm{AOR}=2.148(1.232,3.745)]$.

Regarding to breastfeeding counseling during ANC mothers who were counseled were two times more likely to initiate breastfeeding timey than mothers who were not counseled [AOR $=2.163(1.187,3.942)]$.

Birth place was significantly associated with timely initiation of breastfeeding. Mothers who delivered in health institutions were eight times more likely to practice timely initiation than mothers who delivered at home $[\mathrm{AOR}=8.139(2.089,5.720)]$.

Mode of delivery was significantly associated with timely initiation of breastfeeding. Mothers who were delivered by vaginal/normal delivery were four timely more likely to initiate breastfeeding timely (i.e., within $1 \mathrm{~h}$ )[AOR $=4.094(1.414,8.728)]$.

Religious support was also associated with timely initiation of breastfeeding. Mothers who were supported were two times more likely to initiate breastfeeding timely than mothers who were not supported by religious fathers $[A O R=962(1.113,3.458)]$. (Table 3$)$

\section{DISCUSSION}

Despite maternal and child benefit of timely initiation of breastfeeding practice is well known it not satisfactory in the study area. Only two hundred sixty $(65.0 \%)$ of first time mothers had reported that they initiated breastfeeding within $1 \mathrm{~h}$ of delivery, which is not more far from the national prevalence from 2011 EDHS report for all mothers that is $52.0 \% .^{20}$ The result is comparable to the study conducted in; Ireland $50.7 \%,{ }^{21}$ Axum town $41.6 \%{ }^{18}$ Goba Woreda, South East Ethiopia $52.4 \%,{ }^{22}$ Lagos, Nigeria $59.2 \%,{ }^{23}$ East Africa $61.82 \%$, and South Africa $69.3 \% .{ }^{24,25}$ The result is higher than worldwide prevalence $40 \%$ and $36 \%$ in West and Central Africa, 27\% in South Asia, 31\% generally in Asia, and $39 \%$ in developing countries. ${ }^{24}$ It is also higher than other studies done in; Taif, Saudi Arabia 22\%, ${ }^{26}$ Amhara Regional State $38 \%$, and $41.7 \%$ in Somali regional state. ${ }^{6}$ On the other hand it is lower than the study done in rural part of West Ethiopia $83.1 \%{ }^{27}$ and Tamilnadu, Southern India $97.5 \%{ }^{21}$ The difference might be due to methodological variations between studies, dissimilarities in infant and maternal socio-demographic characteristics like age of the mother and maternal occupation, and other differences like socio-cultural and health service utilization characteristics between respondents of the referenced area and the study place.

The main reasons mentioned by respondents for late initiation of breastfeeding i.e., more than $1 \mathrm{~h}$ of delivery were cesarean section delivery 207 (51.8\%), child illness 75 (18.8\%), maternal illness 24(6.0\%), delayed milk secretion 94 (23.5\%), tradition/ culture $170(48.0 \%)$, lack of information $237(59.8 \%)$, and insufficient breast milk 84 (21.2\%).

Among a number of socio-demographic factors assessed, sex of infant was associated with timely initiation of breastfeeding. Mothers who had a male baby were two times more likely to initiate breastfeeding than mothers who had a female baby. This result is dissimilar with the studies done in EDHS $2011^{27}$ and in Axum Town. ${ }^{18}$ The reason behind could be socio-cultural differences between the community, sex preference that most of our community prefers to have male babies than female babies. Specially in the current situation more female babies are born than male babies. This false perception ultimately decreases the prevalence of timely initiation of breastfeeding and should be changed

Although majority of mothers had antenatal follow up, some of mothers who attended antenatal follow up were not counseled about breastfeeding. Mothers who were counseled during antenatal period were more likely to initiate breastfeeding timely than those who were not counseled. This finding is similar with studies conducted in US, ${ }^{28}$ Logos, Nigeria ${ }^{29}$, and Ireland. ${ }^{30}$ This could be due to the presence of supporting policy system on maternal and child health, breastfeeding guidelines, and training of health workers on breastfeeding practices which can increase their knowledge, attitude and skill of breastfeeding counseling. Counseling during antenatal period enhances mothers understanding and appreciation of the demand of and benefits of early initiation of breastfeeding and creates a positive awareness. Mothers who were counseled during pregnancy prepared themselves psychologically to initiated breastfeed to their infant on time. 


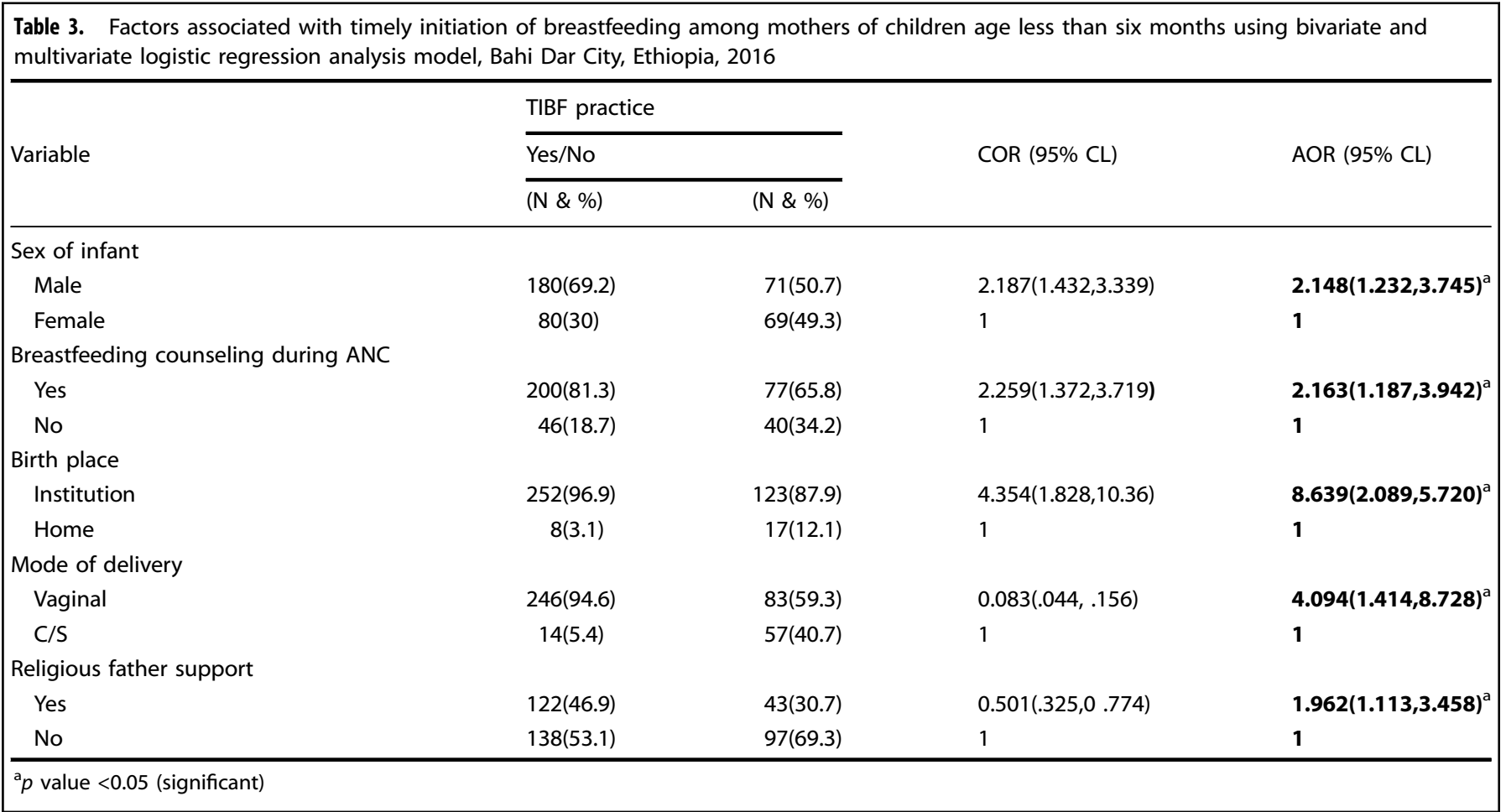

Place of birth was found strongly associated with timely initiation of breastfeeding in this study. Mothers who gave birth in health institutions were more likely to initiate breastfeeding timely than mothers who gave birth at home. This finding is similar with other studies done in Logos, Nigeria ${ }^{29}$, and Ireland. ${ }^{30}$ This could be due to a companion at delivery, post natal counseling of mothers by health workers soon after delivery about timely initiation of breastfeeding and psychological preparation of mothers to initiate breastfeeding timely.

Mode of delivery was significantly associated with timely initiation of breastfeeding. Mothers who had vaginal delivery were more likely to initiate breastfeeding timely than mothers who had cesarean section delivery. This finding is similar to the study in the 2011 nationwide Demographic and Health Survey in Ethiopia, ${ }^{27}$ Goba woreda, South East Ethiopia ${ }^{7}$, and Axum town, Northern Ethiopia. ${ }^{18}$ This could be due to introduction of prelacteal feeding because of poor health status of mothers after cesarean delivery is conducted so that the baby is saved till it starts on breastfeeding. Lower breastfeeding initiation and increased difficulties with breastfeeding in women with cesarean section delivery may be related to a physiologic influence on lactogenesis and poor health systems of the mother related with the effect of aesthesia, which decreases the initiation time until the mother recovers from anesthesia.

On the other hand, religious father support had a significant relation with timely initiation of breastfeeding in the study area. Mothers who were supported by religious fathers were more likely to initiate breastfeeding timely than those mothers who were not supported in which the finding is similar with studies conducted in Zimbabwe, ${ }^{31} \mathrm{Nepal}^{32}$, and Ireland ${ }^{21}$ This could be due to religious leaders are working in collaboration with government to achieve millennium development goals and growth and transformation of Ethiopia. The power traditionally held by religious fathers can strongly affect the beliefs and attitudes of the community so that it brings a great change in community mobilization through mechanisms like church-based social networks, attitudes toward childrearing, and health behaviors. This is due to most of the world's religions place particular emphasis on the total care of the child. This care begins before birth. Once a child is born, one of the most important things a mother can do is breastfeeding, and many religious texts treat breastfeeding as a right and responsibility and as an act of love, sacrifice, and kindness.

Generally the finding of this study will benefit the city administration, regional health bureau, policy makers, and nongovernmental organizations and for health care professionals i.e., health extension workers who are working at community level, nurses, and midwifes with relevant information for future planning and interventions of appropriate strategies to promote and maintain timely initiation breastfeeding. The findings from this study will also contribute to understand timely initiation of breastfeeding and related factors associated with early initiation of breastfeeding in the study area.

As a limitation, recall bias might be introduced, as the mothers might not recall accurately which may under or overestimate the true prevalence of timely initiation of breastfeeding. The study assessed only quantitative aspect not qualitative aspects, i.e., it does not include attitude and beliefs of the community related to TIBF. It is also difficult to establish temporal relationship as the study design was cross-sectional (single point in time snap shot).

\section{CONCLUSION}

The prevalence of timely initiation of breastfeeding in this study was $65.0 \%$, which was not much far from the national prevalence which was surveyed by EDHS 2011 in both multipara and primipara mothers. Among a number of socio-demographic factors, infant sex, counseling about breastfeeding during ANC follow up, birth place, mode of delivery, and religious leaders support were among the independent predictors for higher chance of TIBF practice. Strengthening timely initiation of breastfeeding and provision of antenatal care services, educating mothers both at community and institutional levels as well as strengthening health professionals' knowledge and skills on breastfeeding counseling were recommended. 


\section{ACKNOWLEDGMENTS}

Our first deepest gratitude to Addis Ababa University College of Medicine and Health Science, School of nursing to give the chance to do this research. Finally, we would like to acknowledge our friends who were very interested, encouraged, and helped us to do these research project.

\section{AUTHOR CONTRIBUTIONS}

T.A., T.T. and Y.A. contributed to the design of this study. Authors conceived and designed study, collected, analyzed, and interpreted data; drafted the manuscript for important intellectual content. T.T. reviewed and revised the draft further and approved the final version for submission.

\section{ADDITIONAL INFORMATION}

Ethics approval and consent to participate: Ethical clearance was obtained from Addis Ababa University college of health science institutional review board. And we received ethics committee approval for verbal consent. Then ethical clearance was submitted to Bahir Dar City Administration Mayor's and Bahir Dar City Administration Health Department to get permission for conducting the study. Each study participant was adequately informed about the objective of the study and anticipated benefit and risk of the study by their data collector. Verbal consent was obtained from study participants for protecting autonomy and ensuring confidentiality. Respondents were told the right not to respond to the questions if they don't want to respond or to terminate the interview at any time.

Competing interests: The authors declare no competing interests.

Publisher's note: Springer Nature remains neutral with regard to jurisdictional claims in published maps and institutional affiliations.

\section{REFERENCES}

1. UNICEF. Breastfeeding is the cheapest and most effective life-saver in history. (UNICEF, New York, 2013).

2. Luke, C. et al. Breast-feeding patterns, time to initiation, and mortality risk among newborns in Southern Nepal. J. Nutr. 138, 599-603 (2008).

3. WHO. Global Nutrition Targets 2025 Breastfeeding Policy Brief. (WHO, Geneva, 2010)

4. Roman, P., Qin, D. \& Marta, S. Pregnancy outcome and breastfeeding pattern among vegans, vegetarians and non-vegetarians. FASEB J. 1, 004 (2014).

5. World Health Organization. Global strategy for infant and young child feeding. (WHO, Geneva, 2003).

6. Federal Ministry of Health. IBFAN Report on the Situation of Infant and Young Child Feeding In ETHIOPIA. (Federal Ministry of Health, Addis Ababa, 2015).

7. Lakew et al. Socio-medical determinants of timely breastfeeding initiation in Ethiopia: evidence from the 2011 nationwide Demographic and Health Survey. Int. Breastfeed. J. 10, 24 (2015).

8. Alebel, A. et al. Timely initiation of breastfeeding and its association with birth place in Ethiopia: a systematic review and meta-analysis. Int. Breastfeed. J. 12, 44 (2017).

9. Tewabe, T. Timely initiation of breastfeeding and associated factors among mothers in Motta town, East Gojjam zone, Amhara regional state, Ethiopia, 2015: a cross-sectional study. BMC Pregnancy Childbirth 16, 314 (2016).

10. Berhe, H., Mekonnen, B., Bayray, A. \& Berhe, H. Determinants of breast feeding practices among mothers attending public health facilities, Mekelle, Northern Ethiopia; a cross sectional study. Int J Pharm. Sci. Res. 4, 650 (2013).
11. Bimerew, A., Teshome, M. \& Kassa, G. M. Prevalence of timely breastfeeding initiation and associated factors in Dembecha district, North West Ethiopia: a cross-sectional study. Int. Breastfeed. J. 11, 28 (2016).

12. Tilahun, G., Degu, G., Azale, T. \& Tigabu, A. Prevalence and associated factors of timely initiation of breastfeeding among mothers at Debre Berhan town, Ethiopia: a cross-sectional study. Int. Breastfeed. J. 11, 27 (2016).

13. Setegn, T., Gerbaba, M. \& Belachew, T. Determinants of timely initiation of breastfeeding among mothers in Goba Woreda, South East Ethiopia: a cross sectional study. BMC Public. Health 11, 217 (2011).

14. Adugna, D. T. Women's perception and risk factors for delayed initiation of breastfeeding in Arba Minch Zuria, Southern Ethiopia. Int. Breastfeed. J. 9, 8 (2014).

15. Woldemichael, B. \& Kibie, Y. Timely initiation of breastfeeding and its associated factors among mothers in Tiyo Woreda, Arsi Zone, Ethiopia: a community-based cross sectional study. Clin. Mother Child Health 13, 2 (2016).

16. Fedral Democratic Republic of Ethiopia, Census Commission. Summary and Statistical Report of the 2007 Population and Housing Census. (The Ethiopian statistical agency Bereau, Addis Ababa, 2008).

17. Bahir Dar city adminstration. population census of Bahir Dar city. (Bahir Dar city administration, Bahir Dar, 2016).

18. Mussie, A. et al. Factors associated with timely initiation and exclusive breast feeding among mothers of axum town, Northern Ethiopia. Sci. J. Public. 2(No.5), 394-401 (2014)

19. Sutherland, T. \& PierceB.C. et al. Breastfeeding practices among first-time mothers and across multiple pregnancies.Maternal Child Health J. 16, 1665-1671 (2012).

20. Central Statistical Agency. Ethiopia Demographic and Health Survey 2011 A.A, Ethiopia (ICF International, USA, 2012).

21. Tarrant, RoslynC., Younger, KatherineM., Sheridan-Pereira, Margaret \& Kearney, JohnM. Factors associated with duration of breastfeeding in Ireland: potential areas for improvement. J. Hum. Lact. 27, 262-271 (2011).

22. Gerbaba et al. Determinants of timely initiation of breastfeeding among mothers in Goba Woreda, South East Ethiopia. BMC Public. Health 11, 217 (2011).

23. Olatona, F. A. \& Olufemi, O. A. Breastfeeding practices of mothers of young children in Lagos, Nigeria. Niger. J. Paed 41, 43-47 (2014).

24. Kozhimannil, K. B., Jou, J., Attanasio, L. B., Joarnt, L. K. \& McGovern, P. Medically complex pregnancies and early breastfeeding behaviors: a retrospective analysis. PLOS ONE 9, e104820 (2014).

25. Issaka, A. I., Agho, K. E. \& Renzaho, A. M. Prevalence of key breastfeeding indicators in 29 sub-Saharan African countries: a meta-analysis of demographic and health surveys (2010-2015). BMJ Open 7, e014145 (2017).

26. Sophonneary, P. \& Miriam, D. et al. Breastfeeding trends in Cambodia, and the increased use of breast-milk substitute-why is it a danger? Nutrients $\mathbf{6}$, 2920-2930 (2014).

27. Hailemariam et al. Predictors of early breastfeeding initiation among mothers of children under 24 months of age in rural part of West Ethiopia. BMC Public. Health 15, 1076 (2015)

28. World Health Organization. Global strategy for infant and young child feeding. (WHO, Geneva, 2003).

29. Gladius Jennifer, H. \& Muthukumar, K. Prevalence of early initiation and exclusive breast feeding. J. Clin. Diagn. Res. 6, 1514-1517 (2012).

30. Tarrant, R., . \& Younger, K. \& Sheridan-Pereira, M. \& White, M. \& Kearney, J. The prevalence and determinants of breast-feeding initiation and duration in a sample of women in Ireland.Public Health Nutrition 13, 760-770 (2010).

31. Tiriabaya-Mudzengerere, Ethel \& Mudzengerere, FungaiHamilton The factors that determine exclusive breastfeeding among babies below six months old at Chitungwiza central hospital in Zimbabwe. Int. J. Polit. Good Gov. 4, 916-1 (2013).

32. Hunter, T. \& Cattelona, G. Breastfeeding initiation and duration in first-time mothers: exploring the impact of father involvement in the early post-partum period. Health Promot. Perspect. 4, 132-136 (2014). 